\section{Low-count bacteriuria in refractory idiopathic detrusor overactivity versus controls}

\author{
Colin A. Walsh, ${ }^{1}$ Wendy Allen, ${ }^{1}$ \\ Katrina Parkin, ${ }^{1}$ Chinmoy Mukerjee ${ }^{2}$ \\ Kate H. Moore
}

'Department of Urogynaecology St George Hospital, University of New South Wales, Sydney,

2Department of Microbiology, St George Hospital, University of New South Wales, Sydney, Australia

\section{Abstract}

Background. Previous studies suggest an association between idiopathic detrusor overactivity (ID0) and high-count bacteriuria $\left(>10^{5} \mathrm{CFU} / \mathrm{mL}\right.$ ). Recently, the importance of low-count bacteriuria $\left(10^{3}-10^{5} \mathrm{CFU} / \mathrm{mL}\right)$ in dysuric women with has been recognised. However, the optimal microbiological threshold for women with overactive bladder (OAB) symptoms remains unclear.

Design and Methods. A 2-year prospective cohort study, to examine the incidence of lowcount and high-count bacteriuria in women with refractory IDO (RID0) $v s$ a control group without $\mathrm{OAB}$ symptoms. Women with dysuria, voiding dysfunction or recent urethral instrumentation were excluded. Mid-stream urine (MSU) specimens were collected during acute symptomatic exacerbation in the IDO group and cultured at the $10^{3} \mathrm{CFU} / \mathrm{mL}$ threshold. Statistical analysis was performed using Statsdirect statistical package 2.7.2.

Results. Between November 2007 and November 2009, 218 study MSU specimens were collected. Both the overall incidence of any significant bacteriuria $\geq 10^{3} \mathrm{CFU} / \mathrm{mL}$ $(\mathrm{P}<0.0001)$ and the incidence of low-count bacteriuria $(\mathrm{P}=0.0091)$ were significantly higher in the RID0 women than the controls. There were no baseline differences in age, menopausal status or prior continence surgery between the groups. In the RID0 group, specimens positive for low-count bacteriuria only were less likely to be associated with significant pyuria $\mathrm{P}<0.0001)$ and were cultured from younger women $(\mathrm{P}=0.0009)$, than specimens positive for high-count bacteriuria.

Conclusions. The prevalence of bacteriuria in women with RIDO during symptomatic exacerbation is $40 \%$, which is significantly higher than the incidence in similarly-aged women without $\mathrm{OAB}$. One-third of positive cultures show low-count bacteriuria only. The management of women with RIDO should include a search for bacteriuria, including lowcount bacteriuria.

\section{Introduction}

Since the diagnosis of the unstable bladder was introduced in the 1970 s by Bates and others, ${ }^{1,2}$ continence clinicians have been puzzled by the etiology of this condition. Over the decades, theories on the underlying cause for idiopathic detrusor overactivity (ID0) have ranged from a psychosomatic disorder ${ }^{3}$ to alterations in neuropeptide distribution ${ }^{4,5}$ and urothelial dysfunction. ${ }^{6}$ Most studies on the etiology of ID0 have been conducted in patients with refractory ID0 (RID0), that is, those women who do not respond to conventional anti-cholinergic therapy. ${ }^{7}$ Although there is little consensus on the precise definition of refractory, longitudinal studies provide evidence that a substantial proportion of patients with IDO do not respond to standard management. ${ }^{8,9}$

With the introduction of the broader term overactive bladder $(O A B)$, the exclusion of significant bacteriuria became an essential diagnostic criterion for this syndrome. However, there has been considerable evolution in the diagnostic criteria for significant bacteriuria in recent years, with increasing recognition of the importance of low-count bacteriuria $\left(10^{3}\right.$ $10^{5} \mathrm{CFU} / \mathrm{mL} .{ }^{10}$ Indeed, both the Infectious Diseases Society of America and the European Association of Urology have stipulated that the quantitative threshold for significant bacteriuria in acutely dysuric women should include low bacterial counts. ${ }^{11,12}$

However, the appropriate microbiological threshold in excluding significant bacteriuria in women the $\mathrm{OAB}$ syndrome without dysuria remains unclear. Two recent studies have demonstrated a substantial $25-30 \%$ incidence of bacteriuria $\geq 10^{3} \mathrm{CFU} / \mathrm{mL}$ in women with OAB. ${ }^{13,14}$ The background comparative incidence of low-count bacteriuria in control women without $\mathrm{OAB}$ symptoms was not reported by these authors. The present study was carried out in a tertiary urogynecology center, in which IDO has been the major focus of research for almost two decades. This study was precipitated by the anecdotal finding that many women with RIDO who presented with an acute exacerbation of their urge incontinence symptoms, but no dysuria, were found to have bacterial cystitis. In view of the recent shift in focus towards low-count bacteriuria, we undertook a prospective comparative analysis of low-count and high-count bacteriuria in women with RIDO $v s$ a control group of women without $\mathrm{OAB}$ symptoms.
Correspondence: Professor Kate Moore, Pitney Clinical Sciences Building, St George Hospital, Kogarah, NSW 2217 Australia.

Tel: +61.2.91132054.

E-mail:k.moore@unsw.edu.au

Key words: bacteriuria, detrusor overactivity, overactive bladder, refractory, urinary tract infection.

Contributions: CW, data collection, data analysis, manuscript preparation; WA, data collection; KP, data collection; CM, Microbiological analysis; KM, study design, manuscript editing.

Conflict of interest: the authors report no conflicts of interest.

Funding: Colin Walsh is partially funded by a University of New South Wales International Research Scholarship.

Received for publication: 25 April 2011. Accepted for publication: 30 June 2011.

This work is licensed under a Creative Commons Attribution NonCommercial 3.0 License (CC BYNC 3.0).

() Copyright C.A. Walsh et al., 2011

Licensee PAGEPress, Italy

Urogynaecologia 2011; 25:e4

doi:10.4081/uij.2011.e4

\section{Design and Methods}

A 2-year prospective cohort study of women aged 18-80 years with refractory ID0. RID0 was defined as failure to respond to $\geq 2$ anticholinergic agents coupled with out-patient bladder training for $\geq 1$ year, with persistent disabling symptoms on frequency-volume char. ${ }^{15}$ All study participants had urodynamicallyproven DO without neurological disease. Eligible women were recruited and asked to submit a standard mid-stream urine (MSU) specimen for culture and sensitivity whenever their OAB symptoms (frequency, urgency, nocturia, urge incontinence) were acutely exacerbated. Women with co-existent stress incontinence were not excluded, provided the patient reported $\mathrm{OAB}$ symptoms to be the most bothersome. Full inclusion and exclusion criteria are detailed in Table 1. Women attending our unit with pure stress incontinence or mild pelvic organ prolapse, who denied all OAB symptoms on direct questioning, were asked to supply control MSU specimens for comparative analysis. All women with IDO in our unit are initially managed with lifestyle advice and bladder training, with anti-cholinergic medication added in as required. Peri- and postmenopausal women are treated with regular topical vaginal estrogen. All study patients 
were instructed on clean-catch MSU collection according to a standard regime to minimise contamination. Briefly, the urethral meatus is cleansed, the labia parted, voiding commenced and a sterile container is inserted into the urinary stream and removed, without interruption to the stream. Each MSU specimen was refrigerated at $4^{\circ} \mathrm{C}$ immediately after collection and transported to the laboratory in a refrigerated container within 2 hours. The study was performed in collaboration with our Microbiology department and MSU specimens from study participants were cultured at the $10^{3} \mathrm{CFU} / \mathrm{mL}$ threshold (to include low-count bacteriuria) rather than the usual $10^{5} \mathrm{CFU} / \mathrm{mL}$. Specimens were cultured using Horse Blood Agar incubated at $35^{\circ} \mathrm{C}$ in $7 \% \quad \mathrm{CO}_{2}$ and McConkey's agar incubated at $35^{\circ} \mathrm{C}$ in air. These culture media grow all known pathogens and contaminants. Pyuria was determined using haemocytometer counts on uncentrifuged urine specimens, with counts of $>10$ white blood cells (WBC)/ $\mu \mathrm{L}$ considered significant. Any bacteriuria $\geq 10^{3} \mathrm{CFU} / \mathrm{mL}$ was considered a positive urine culture, in accordance with recent guidelines. ${ }^{12}$ Specimens with bacteriuria $<10^{3} \mathrm{CFU} / \mathrm{mL}$ were considered sterile. Women with positive cultures received 5 days of appropriate oral antibiotic therapy, according to sensitivity testing.

Categorical data were analysed using Fisher's exact test. Data collated for age showed evidence of non-normality using the Shapiro-Wilk's test. As such, median age was compared using the Mann-Whitney test for non-parametric data. Two-tailed $P$ values were used throughout and the $5 \%$ level was considered significant. Statistical analysis was performed using Statsdirect statistical package 2.7.2 (Statsdirect Ltd, Cheshire, UK).

\section{Results}

Between November 2007 and November 2009, 50 women with urodynamically-proven non-neurogenic D0, who met our strict criterion for refractory, were recruited into the study. Fifty control women, who denied all OAB symptoms, were also recruited. There were no differences in age $(\mathrm{P}=0.15)$, menopausal status $(\mathrm{P}=0.50)$ or history of prior continence surgery $(\mathrm{P}=0.17)$ between the RID0 and control groups (Table 2). The median duration of $\mathrm{OAB}$ symptoms for the RID0 women was 10 years and they had trialled a median of 3 anti-cholinergic medications. Over the 2-year study period, 168 MSU specimens were provided by the RID0 group and 50 MSU specimens from the control group, for a total 218 study urine specimens. Women with RID0 provided a median of 3 urine samples during the study period and control women provided one MSU per patient.
The incidence of any bacteriuria $\geq 10^{3}$ $\mathrm{CFU} / \mathrm{mL}$ was significantly higher in the MSU specimens obtained from women with RID0 compared to those without $\mathrm{OAB}$ symptoms $(\mathrm{P}<0.0001$, Table 3). Analysis of low-count $\left(10^{3}-10^{5} \mathrm{CFU} / \mathrm{mL}\right)$ bacteriuria only also demonstrated a significant difference between groups ( $\mathrm{P}=0.0091$, Table 3). Overall, at least one positive culture was obtained from $56 \%$ (28/50) of women with RIDO. E. coli was the predominant microbiological organism cultured from women with RID0, accounting for $58 \%(38 / 65)$ of total positive cultures (Table 4$)$. Subset analysis by bacteria showed that the

only significant difference was with streptococci; the proportion of specimens positive for streptococci was higher in the low-count specimens (6/21) vs the high-count specimens (2/44; $\mathrm{P}=0.01$; Table 4). In the RID0 group, specimens positive for high-count bacteriuria were more likely to be associated with significant pyuria $(84 \% ; 37 / 44)$ than those positive for low-count bacteriuria $(23 \%$; $5 / 21)$ only $(\mathrm{P}<0.0001$; Table 4).

The median age of women with RID0 in this study was 62.5 (Inter-quartile range 53-70) years. Overall, among the women with RID0, bacteriuric urine specimens were collected

Table 1. Study inclusion and exclusion criteria.

\begin{tabular}{|c|c|}
\hline Inclusion criteria & Exclusion criteria \\
\hline Female aged $18-80$ years & Current dysuria or fever \\
\hline Idiopathic DO & $\begin{array}{l}\text { Voiding dysfunction } \\
\text { (post-void residual bladder volume } \geq 100 \mathrm{~mL} \text { ) }\end{array}$ \\
\hline $\begin{array}{l}\text { Pure DO or mixed incontinence with } \mathrm{OAB} \\
\text { symptoms most bothersome }\end{array}$ & Suspicion of neurogenic or post-surgical DO \\
\hline Refractory to anti-cholinergic therapy & Pregnancy or $<6$ weeks post-partum \\
\hline English-speaking & Recent ( $<2$ weeks) urethral instrumentation \\
\hline
\end{tabular}

Table 2. Baseline demographic data.

\begin{tabular}{lrcc} 
& Refractory IDO & Controls & P \\
Median Age (IQR) & $62.5(53-70)$ & $56.5(48-67)$ & 0.15 \\
Post-menopausal \% (n) & $76(38 / 50)$ & $68(34 / 50)$ & 0.50 \\
\hline Prior continence surgery \% (n) & $32(16 / 50)$ & $18(9 / 50)$ & 0.17 \\
\hline
\end{tabular}

IDO, idiopathic destrusor overactivity; IQR, inter-quartile range.

Table 3. Results of formal culture at $10^{3} \mathrm{CFU} / \mathrm{mL}$ threshold.

\begin{tabular}{|c|c|c|c|}
\hline 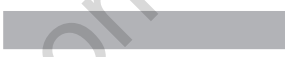 & Refractory IDO & Controls & $\mathbf{P}$ \\
\hline Study participants & 50 & 50 & - \\
\hline Study MSU specimens & 168 & 50 & - \\
\hline Sterile $\left(<10^{3} \mathrm{CFU} / \mathrm{mL}\right)$ & $61 \%(103 / 168)$ & $94 \%(47 / 50)$ & - \\
\hline Bacteriuria $\geq 10^{3} \mathrm{CFU} / \mathrm{mL}$ & $39 \%(65 / 168)$ & $6 \%(3 / 50)$ & $<0.0001$ \\
\hline $\begin{array}{l}\text {-High-count bacteriuria } \\
\left.\text { (>10 } 0^{5} \mathrm{CFU} / \mathrm{mL}\right)\end{array}$ & $26 \%(44 / 168)$ & $4 \%(2 / 50)$ & 0.0003 \\
\hline $\begin{array}{l}\text {-Low-count bacteriuria } \\
\left(10^{3}-10^{5} \mathrm{CFU} / \mathrm{mL}\right)\end{array}$ & $17 \%(21 / 124) *$ & $2 \%(1 / 48)^{*}$ & 0.0091 \\
\hline
\end{tabular}

Table 4. Bacterial etiology by quantity of bacteriuria in women with refractory idiopathic destrusor overactivity.

\begin{tabular}{lccc} 
Bacteria & $\begin{array}{c}\text { Low-count } \\
\left(10^{3}-10^{5} \mathrm{CFU} / \mathrm{mL}\right)\end{array}$ & $\begin{array}{c}\text { High-count } \\
\left(>10^{5} \mathrm{CFU} / \mathrm{mL}\right)\end{array}$ & $\mathrm{P}$ \\
\hline E. coli & $11(1)$ & $27(23)$ & 0.59 \\
Streptococci & $6(1)$ & $2(1)$ & 0.01 \\
\hline Klebsiella & $1(1)$ & $6(5)$ & 0.41 \\
Pseudomonas & $1(0)$ & $3(3)$ & $>0.99$ \\
\hline Enterococcus & $1(1)$ & $5(4)$ & 0.65 \\
Other & $1(1)$ & $1(1)$ & - \\
\hline Total & $21(5)$ & $44(37)$ & - \\
\hline
\end{tabular}

CFU, colony-forming units. 
from older women when compared to specimens which were sterile ( 67 years $v s 63$ years respectively; $\mathrm{P}=0.04$ ). However, within the positive specimens, those which grew lowcount bacteriuria were collected from significantly younger women than those which grew high-count bacteriuria (58 years vs 67 years respectively; $\mathrm{P}=0.0009$ ).

Among women with RID0, $32 \%$ (16/50) had a history of previous continence surgery, who supplied 63 study urine specimens. MSU specimens obtained from women with previous continence surgery were significantly more likely to grow bacteriuria $\geq 10^{3} \mathrm{CFU} / \mathrm{mL}(35 / 63)$ compared to those from women with RID0 and no history of continence surgery (30/105; $\mathrm{P}=0.0006)$, despite no difference in PVR between the sub-groups $(\mathrm{P}=0.24)$ and $\mathrm{PVR}<100 \mathrm{~mL}$ in all women with RID0.

All women with cultures positive for lowcount or high-count bacteriuria received a course of antibiotic therapy. Although the severity of urgency was generally reduced on frequency-volume chart in the RID0 group following antibiotics, formal assessment of urgency symptoms was not undertaken in this study.

\section{Discussion}

Extensive research into the etiology of ID0 has been undertaken in recent decades but the underlying cause remains elusive. An association between $\mathrm{OAB}$ symptoms and bacterial cystitis has been postulated. ${ }^{16-18}$ The concept of refractory IDO is frequently mentioned in the literature but poorly defined. ${ }^{7}$ A longitudinal study of Australian women found a $65 \%$ rate of non-responders to treatment at a median follow-up of 8 years. ${ }^{8} \mathrm{~A}$ recent long-term study of UK women reported an $88 \%$ rate of persistent ID0 on urodynamics at $\geq 10$ years following instigation of treatment. ${ }^{9}$ Clinical management of this refractory group is moving towards sacral neuromodulation and intravesical neurotoxin..$^{19}$ These interventions are invasive, expensive and not without risk to the patient, making the identification of potentially-treatable exacerbating factors, such as bacteriuria, imperative.

In parallel with the work on the etiology of ID0, our understanding of what constitutes significant bacteriuria in the diagnosis of urunary tract infection (UTI) has developed considerably. The traditional definition of significant bacteriuria [ $>10^{5}$ colony-forming units (CFU) per milliliter) was described in 1957 by Edward Kass, a Harvard nephrologist. ${ }^{20}$ However, Kass was mainly interested in a practical threshold which could be used to distinguish probable infected specimens from those likely to be simply contaminated, at a time when pyelonephritis was a major source of mortality. ${ }^{20,21} \mathrm{He}$ did acknowledge that lesser degrees of bacteriuria may be associated with infection. Since then, the focus has shifted towards women with lower urinary tract symptoms; numerous studies have found that 30 $50 \%$ of urine cultures from acutely dysuric women fail to meet Kass' microbiological standard. ${ }^{10}$ Expert guidelines now support the inclusion of low-count bacteriuria in women with acute dysuria. ${ }^{11,12}$ In contrast, there is a paucity of data on the incidence of bacteriuria $10^{3}-10^{5} \mathrm{CFU} / \mathrm{mL}$ in women with ID0 without dysuria. Previous studies linking female urinary incontinence and bacterial cystitis were performed using Kass' older, less sensitive microbiological definition. Moore et al. reported bacterial cystitis in $6 \%$ of women with DO undergoing urodynamics, compared to $1 \%$ in stress incontinent controls. ${ }^{16}$ A study of 913 post-menopausal women found the basal rate of incontinence to be higher for women who experienced UTIs, even after controlling for the acute incontinence surrounding an infective episode. ${ }^{17}$ Neither of these studies considered low-count bacteriuria. The presence of bacteriuria also impacts on the accuracy of urodynamic testing. Bhatia et al. performed repeat urodynamic studies on 15 women who had significant bacteriuria $\left(\geq 10^{5} \mathrm{CFU} / \mathrm{mL}\right.$ ) during initial cystometric testing. They found that the incidence of D0 fell by $50 \%$ after eradication of the UTI, although urodynamic parameters such as first desire to void and maximum cystometric capacity were unchanged. ${ }^{18}$

Currently, there is a dearth of evidence on the significance of bacteriuria, particularly low-count bacteriuria in women with frequency/urgency/nocturia. Khasriya et al. reported on 470 women with lower urinary tract symptoms (LUTS) without dysuria. ${ }^{13}$ By incorporating low-count bacteriuria, the incidence of positive specimens increased from 15\% (using the traditional culture threshold of $10^{5}$ $\mathrm{CFU} / \mathrm{mL}$ ) to $29 \%$. However, this study was primarily examining the role of dipstick urinalysis and the specimens were obtained from a wide range of women without urodynamic diagnoses. A similar German study reported an almost identical 28\% incidence of bacteriuria $\geq 10^{3} \mathrm{CFU} / \mathrm{mL}$ in women with $\mathrm{OAB}$ without symptoms of acute UTI (dysuria, fever or haematuria). ${ }^{14}$ However, neither study presented a suitable control group to allow comparative analysis (although the former paper does include a small, mixed-gender control group). Thus, while an incidence of $28-29 \%$ appears high (and likely is), background data regarding the incidence in the general female population is not, to our knowledge, available.

The aim of the present study was to examine the incidence of bacteriuria and low-count bacteriuria among a severely affected group of women with RID0, compared to the incidence in women without $\mathrm{OAB}$ symptoms. Only women with ID0 were recruited as, compared to women with $\mathrm{OAB}$ syndrome without DO, women with urodynamically-proven DO have more incontinent episodes and earlier abnormal sensory symptoms. ${ }^{22}$ Furthermore, this group would generally be considered candidates for sacral neuromodulation or intravesical neurotoxin, which may be inappropriate if bacteriuria has not been excluded. The present study finds that, in women with RID0, the incidence of bacteriuria during an episode of symptomatic exacerbation, using a sensitive microbiological threshold, is $39 \%$. This is considerable and is higher than similar incidences quoted for women with OAB symptoms only. ${ }^{14}$ Furthermore, our data show that the comparative incidence amongst similarly aged women without $\mathrm{OAB}$ symptoms is significantly lower (6\%, Table 3$)$, which has not previously been reported.

The European Association of Urology has recently published guidelines which support the treatment of low bacterial counts in acute UTI. ${ }^{12}$ These echo guidelines published in 1992 by the Infectious Diseases Society of America (IDSA). ${ }^{11}$ However, it was also noted that a marginally higher threshold $\left(\geq 10^{3} \mathrm{CFU} / \mathrm{mL}\right.$ ) improved specificity ( $90 \%$ vs $85 \%$ ) with little loss of sensitivity ( $80 \%$ vs $95 \%$ ) compared to $\geq 10^{2}$ and, in addition, could be more easily identified by routine microbiological techniques. $^{12}$ Despite these expert guidelines, many laboratories continue to use the traditional threshold of $\geq 10^{5} \mathrm{CFU} / \mathrm{ml}$ when determining bacteriuria that requires treatment. ${ }^{23}$ Indeed, the recent joint consensus document on the terminology of pelvic floor dysfunction by the International Continence Society/ International Urogynaecological Association, endorses a threshold of $>10^{5} \mathrm{CFU} / \mathrm{ml}$ for voided specimens in the diagnosis of UTI. ${ }^{24}$ The present study shows that, among women with RID0, one-third of bacteriuric specimens grow low-count bacteriuria only, which would be missed if a $>10^{5} \mathrm{CFU} / \mathrm{mL}$ threshold is maintained.

The impact of age on rates of bacteriuria in this study is notable. In general, positive urine cultures were obtained from older women, which is consistent with previous reports..$^{25}$ However, amongst the positive cultures, those positive for low-count bacteriuria only were obtained from significantly younger women than those with high-count bacteriuria. Several theories have been proposed to explain the phenomenon of low-count bacteriuria, including urinary dilution, an early phase of infection, the presence of an inhibitor or following antibiotic therapy. ${ }^{26}$ An interesting Israeli study examined the natural history of low-count and high-count UTI over 2 days without antibiotic treatment. Among women 
with a baseline low-count UTI, 50\% had progressed to a high-count infection after 48 hours, which substantiates the theory that low-count bacteriuria simply represents an earlier stage in the infective process. ${ }^{27}$ To our knowledge, a possible association between low bacterial counts younger aged women has not previously been suggested.

Pyuria has traditionally been used to distinguish true infection from colonisation. Most women with bacteriuria $>10^{5} \mathrm{CFU} / \mathrm{mL}$ will have pyuria. Recent expert guidelines include pyruia as part of the diagnostic algorithm for UTI. ${ }^{12}$ However the relationship between bacteriuria $10^{3}-10^{5} \mathrm{CFU} / \mathrm{mL}$ and pyuria is less clear. The previous study of 470 women with $\mathrm{OAB}$ by Khasriya et al. noted a trend towards reduced pyuria in low-count compared to highcount bacteriuria $(\mathrm{P}=0.078) .{ }^{13}$ Another study, on bladder biopsies from patients with the $\mathrm{OAB}$ syndrome, found that the presence of significant pyuria in urine did not predict the histological finding of chronic cystitis.28 Furthermore, the high rate of natural progression of low-count to high-count bacteriuria suggests that low bacterial counts, even in the absence of pyuria, cannot be dismissed as clinically insignificant. ${ }^{27}$

In the present study, bacteriuria $10^{3}-10^{5}$ $\mathrm{CFU} / \mathrm{mL}$ was significantly less likely to be associated with pyuria $(\mathrm{P}<0.0001)$. It is notable that destruction of urinary leukocytes begins almost immediately after specimen collection. We refrigerated our specimens immediately at $4^{\circ} \mathrm{C}$ and transported them to the laboratory within 2 hours in all cases. However, refrigeration slows but does not eliminate WBC lysis. White cell destruction in refrigerated specimens is approximately $20 \%$ in the first 2 hours after collection, ${ }^{29}$ which may have impacted on the rates of pyuria reported here although one would expect all specimens to be equally vulnerable to this effect.

We acknowledge a number of limitations with the present study. Firstly, microbiological analysis was performed on MSU specimens rather than CSU, which may overestimate the incidence of bacteriuria. However, most women with ID0 will continue to provide midstream, rather than catheter, specimens at times of worsening $\mathrm{OAB}$ symptoms, thus enhancing the clinical applicability of our findings. Secondly, although anecdotal evidence suggested an improvement in ID0 symptoms following antibiotic treatment of bacteriuria, formal assessment of patients' symptoms preand post-treatment was not undertaken. Statistical evidence of symptomatic improvement following antimicrobial therapy of women with IDO and bacteriuria will likely require a randomized placebo controlled trial. Finally, the debate regarding the clinical importance of low-count bacteriuria without pyuria will continue. Although several studies have consistently demonstrated reduced rates of pyuria in lower bacterial counts, objective evidence of symptomatic improvement will be needed to substantiate the notion that, among women with ID0, bacteriuria without pyuria is clinically meaningful.

\section{Conclusions}

A substantial proportion of women with ID0 are refractory to standard treatment and contemporary management of these cases may include invasive neuromodulation and intravesical neurotoxin. Recent expert guidelines endorse the inclusion of low bacterial counts $\left(10^{3}-10^{5} \mathrm{CFU} / \mathrm{mL}\right)$ in the diagnosis of acute UTI but the incidence of this low-count bacteriuria in women with refractory IDO is poorly studied.

In the present study, we were quite surprised to find that almost $40 \%$ of women with RIDO and an acute exacerbation of symptoms had significant bacteriuria on MSU. For the first time, we can report that this incidence is significantly higher than among a control group of similarly-aged women without $\mathrm{OAB}$ symptoms. One-third of positive cultures grew low-count bacteriuria only. Low-count bacteriuria was seen in younger women and was more likely to resolve following appropriate antibiotic therapy. The management of women with RID0 experiencing an acute worsening of symptoms should include a search for bacteriuria and a low-count microbiological threshold should be considered.

\section{References}

1. Bates CP. The unstable bladder. Clin Obstet Gynaecol 1978;5:109-22

2. Ramsden PD, Smith JC, Pierce JM, Ardran GM. The unstable bladder--fact or artefact? Br J Urol 1977;49:633-9.

3. Frewen WK. An objective assessment of the unstable bladder of psychosomatic origin. Br J Urol 1978;50:246-9.

4. Gu J, Restorick JM, Blank MA, et al. Vasoactive intestinal polypeptide in the normal and unstable bladder. Br $\mathrm{J}$ Urol 1983;55:645-7.

5. Smet PJ, Moore KH, Jonavicius J. Distribution and colocalization of calcitonin gene-related peptide, tachykinins, and vasoactive intestinal peptide in normal and idiopathic unstable human urinary bladder. Lab Invest 1997;77:37-49.

6. Kanai A, Andersson KE. Bladder afferent signaling: recent findings. J Urol 2010; 183:1288-95.

7. Nitti VW, Kopp Z, Lin AT, et al. Can we predict which patient will fail drug treatment for overactive bladder? A think tank discussion. Neurourol Urodyn 2010; 29:652-7.

8. Morris AR, Westbrook JI, Moore KH. A longitudinal study over 5 to 10 years of clinical outcomes in women with idiopathic detrusor overactivity. BJOG 2008; 115:23946.

9. Garnett S, Swithinbank L, Ellis-Jones J, Abrams P. The long-term natural history of overactive bladder symptoms due to idiopathic detrusor overactivity in women. BJU Int 2009;104:948-53.

10. Walsh CA, Moore KH. Overactive bladder in women: does low-count bacteriuria matter? A review. Neurourol Urodyn 2011; 30:32-7.

11. Rubin RH, Shapiro ED, Andriole VT, et al. Evaluation of new anti-infective drugs for the treatment of urinary tract infection. Infectious Diseases Society of America and the Food and Drug Administration. Clin Infect Dis 1992; 15 Suppl 1:S216-27.

12. Grabe M, Bishop MC, Bjerklund-Johansen TE et al. Guidelines on urological infections. European Association of Urology. 2009. Available from: http://www.uroweborg/nc/professional-resources/guidelines/online

13. Khasriya R, Khan $S$, Lunawat $R$, et al. The inadequacy of urinary dipstick and microscopy as surrogate markers of urinary tract infection in urological outpatients with lower urinary tract symptoms without acute frequency and dysuria. $\mathrm{J}$ Urol 2010;183:1843-7.

14. Hessdoerfer E, Jundt K, Peschers U. Is a dipstick test sufficient to exclude urinary tract infection in women with overactive bladder? Int Urogynecol J Pelvic Floor Dysfunct 2011;22:229-32.

15. Moore KH, Nickson P, Richmond DH, et al. Detrusor mast cells in refractory idiopathic instability. Br J Urol 1992;70:17-21.

16. Moore KH, Simons A, Mukerjee C, Lynch $\mathrm{W}$. The relative incidence of detrusor instability and bacterial cystitis detected on the urodynamic-test day. BJU Int 2000; 85:786-92.

17. Moore EE, Jackson SL, Boyko EJ, et al. Urinary ncontinence and urinary tract infection: temporal relationships in postmenopausal women. Obstet Gynecol 2008;111:317-23.

18. Bhatia NN, Bergman A. Cystometry: unstable bladder and urinary tract infection. $\mathrm{Br}$ J Urol 1986; 58:134-7.

19. Campbell JD, Gries KS, Watanabe JH, et al. Treatment success for overactive bladder with urinary urge incontinence refractory to oral antimuscarinics: a review of published evidence. BMC Urol 2009; 9:18.

20. Kass EH. Bacteriuria and the diagnosis of infections of the urinary tract; with observations on the use of methionine as a uri- 
nary antiseptic. AMA Arch Intern Med 1957;100:709-14.

21. Kass EH. Asymptomatic infections of the urinary tract. Trans AM Physiol 1956; 69:56-64.

22. Guralnick ML, Grimsby G, Liss M, et al. Objective differences between overactive bladder patients with and without urodynamically proven detrusor overactivity. Int Urogynecol J Pelvic Floor Dysfunct 2010; 4:325-9.

23. Wilson ML, Gaido L. Laboratory diagnosis of urinary tract infections in adult patients. Clin Infect Dis 2004;38:1150-8.

24. Haylen BT, de Ridder D, Freeman RM, et al. An International Urogynecological
Association (IUGA)/International Continence Society (ICS) joint report on the terminology for female pelvic floor dysfunction. Neurourol Urodyn 2010; 29:4-20.

25. Ribeiro RM, Rossi P, Guidi HG, Pinotti JA. Urinary tract infections in women. Int Urogynecol J Pelvic Floor Dysfunct 2002; 13:198-203.

26. Kunin CM, White LV, Hua TH. A reassessment of the importance of low-count bacteriuria in young women with acute urinary symptoms. Ann Intern Med 1993;119: 454-60.

27. Arav-Boger R, Leibovici L, Danon YL. Urinary tract infections with low and high colony counts in young women.
Spontaneous remission and single-dose vs multiple-day treatment. Arch Intern Med 1994; 154:300-4.

28. Lunawat R, Khasriya R, Bishara S, et al. Histological evidence of ubiquitous occurrence of chronic cystitis in urothelial biopsies from patients with symptoms of overactive bladder and normal urinalysis. Neurourol Urodyn 2009;28: 754-5.

29. Khan S, O'Connor D, Khasriya R, et al. The time course of white cell destruction in urine samples and the necessity of immediate analysis. Int Urogynecol J 2008;19: S38-39. 